Portland State University

PDXScholar

\title{
Understanding Individual and Family Experiences Associated with DUP: Lessons from the Early Assessment and Support Alliance (EASA) Program in Oregon, USA
}

Ryan P. Melton

Portland State University, rymelton@pdx.edu

Shannon Blajeski

Portland State University

Diana Glasser

Portland State University

Follow this and additional works at: https://pdxscholar.library.pdx.edu/rri_facpubs

Part of the Community Health Commons

Let us know how access to this document benefits you.

\section{Citation Details}

Melton, R., Blajeski, S. \& Glasser, D. Understanding Individual and Family Experiences Associated with DUP: Lessons from the Early Assessment and Support Alliance (EASA) Program in Oregon, USA. Community Ment Health J 56, 1121-1127 (2020). https://doi.org/10.1007/s10597-020-00599-3

This Post-Print is brought to you for free and open access. It has been accepted for inclusion in Regional Research Institute by an authorized administrator of PDXScholar. Please contact us if we can make this document more accessible: pdxscholar@pdx.edu. 


\section{Understanding Individual and Family Experiences Associated with DUP: Lessons from the Early Assessment and Support Alliance (EASA) program in Oregon, USA. \\ --Manuscript Draft--}

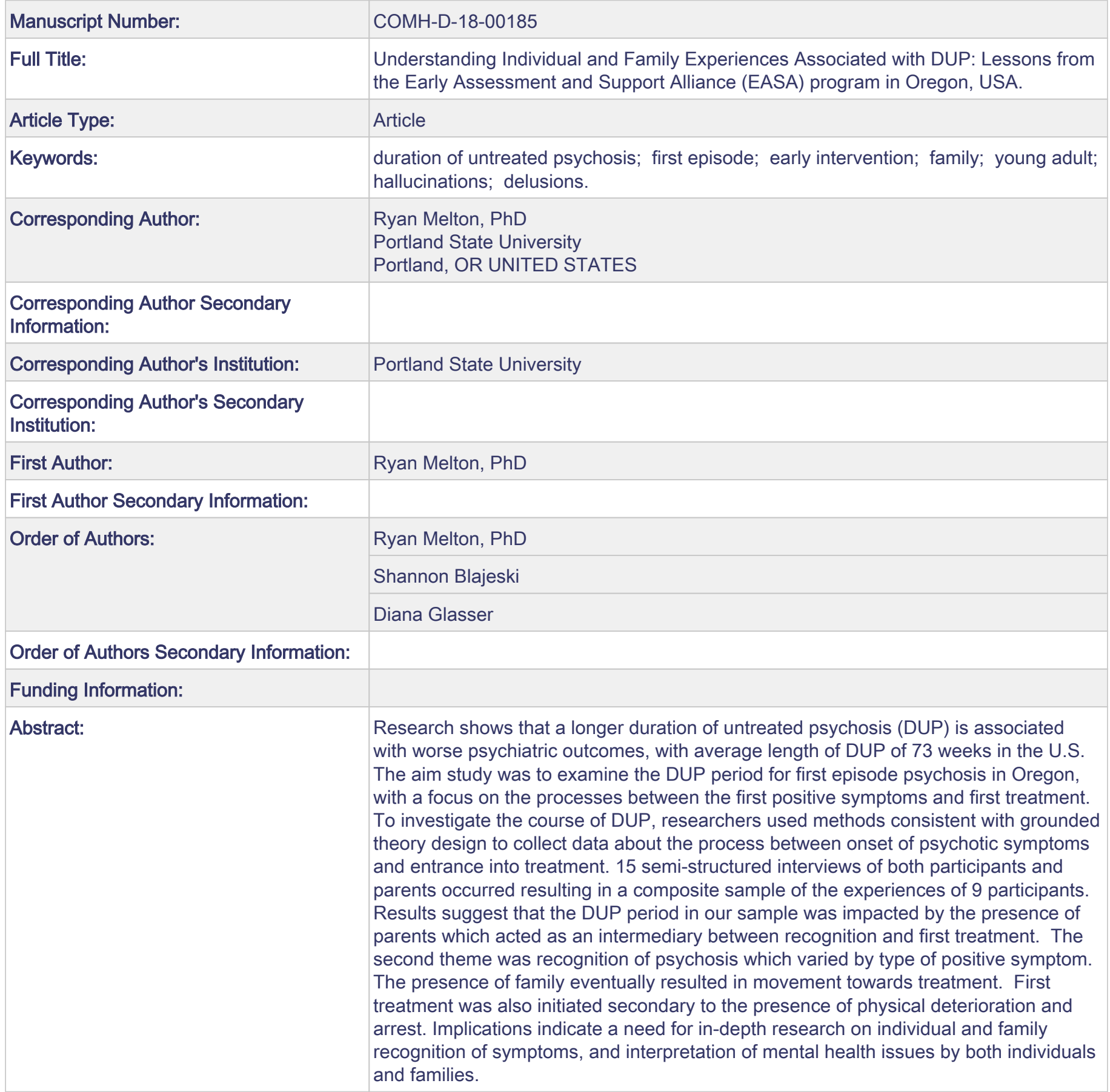


Understanding Individual and Family Experiences Associated with DUP: Lessons from the Early Assessment and Support Alliance (EASA) program in Oregon, USA.

\author{
Ryan Melton, Ph.D. \\ EASA Clinical Training Director \\ Regional Research Institute (RRI) \\ Portland State University \\ Suite 918 \\ 1600 SW 4th Ave. \\ Portland OR. 97201 \\ rymelton@pdx.edu \\ 971-218-9251 \\ Shannon Blajeski, MSW \\ EASA Research Assistant \\ Regional Research Institute (RRI) \\ Portland State University \\ Suite 918 \\ 1600 SW 4th Ave. \\ Portland OR. 97201 \\ Diana Glasser, BA \\ EASA Intern \\ Regional Research Institute (RRI) \\ Portland State University \\ Suite 918 \\ 1600 SW 4th Ave. \\ Portland OR. 97201
}





\begin{abstract}
Research shows that a longer duration of untreated psychosis (DUP) is associated with worse psychiatric outcomes, with average length of DUP of 73 weeks in the U.S. The aim study was to examine the DUP period for first episode psychosis in Oregon, with a focus on the processes between the first positive symptoms and first treatment. To investigate the course of DUP, researchers used methods consistent with grounded theory design to collect data about the process between onset of psychotic symptoms and entrance into treatment. 15 semi-structured interviews of both participants and parents occurred resulting in a composite sample of the experiences of 9 participants. Results suggest that the DUP period in our sample was impacted by the presence of parents which acted as an intermediary between recognition and first treatment. The second theme was recognition of psychosis which varied by type of positive symptom. The presence of family eventually resulted in movement towards treatment. First treatment was also initiated secondary to the presence of physical deterioration and arrest. Implications indicate a need for in-depth research on individual and family recognition of symptoms, and interpretation of mental health issues by both individuals and families.
\end{abstract}

Keywords: duration of untreated psychosis, first episode, early intervention, family, young adult, hallucinations, delusions. 


\section{Introduction}

Evidence indicates that a longer duration of untreated psychosis (DUP) during the first-episode period (FEP) is associated with worse psychiatric and social functioning. A prolonged DUP is associated with negative symptoms (Franz, et al., 2010; Jansen, Wøldike, Haahr, \& Simonsen, 2015 1,2), altered neurochemistry (Del Vecchio, Luciano, Sampogna, De Rosa, Giacco, Tarricone, Catapano \& Fiorillo, 2015) and social withdrawal (Franz, et al., 2010; Jansen, et al., 2015; Del Vecchio, et. Al., 2015; Drake, Haley, Akhtar \& Lewis, 2000). It has also been found to have an impact on family and societal factors (Franz, et al., 2010; Drake et, al., 2000). Research on early psychosis underscores the "critical period" which "extends out to a maximum of 5 years from onset of illness" and emphasize the importance of intervention during this time window (Del Vecchio, et. Al., 2015).

Assessment of DUP is complex due to barriers to accessing care at the community level and by the variation in help-seeking among individuals and their family members. In addition, psychosis is usually identified after the emergence of positive symptoms, while prodromal symptoms tend to go unnoticed (Judge, Estroff, Perkins, \& Penn, 2008). In addition to focusing on reducing DUP, a further issue is that of treatment retention for people with psychosis. Although DUP can at times be reduced, many people with severe mental illness disengage from care. Even when psychosis is correctly identified and treatment initiated it does not always result in treatment maintenance. This can result in the catastrophic cycle of psychiatric decline and associated social and economic losses. The aim of this study was to explore the DUP experiences of young adults between the first positive symptom of psychosis and first psychiatric treatment and to propose a pilot model of these DUP processes for Oregonians experiencing first episode psychosis.

\section{Background}

This study seeks to explore the DUP period for those young adults participating in the local earlyintervention program. The Early Assessment and Support Alliance (EASA) is a coordinated specialty care early psychosis program and is the longest running early psychosis program in the United States (Melton, Roush, Sale, Wolf, Usher, Rodriguez, \& McGorry, 2013). EASA has 28 programs in Oregon, resulting in all Oregon residents with access to an early psychosis program. EASA serves individuals aged 15-25, who are experiencing first episode psychosis or psychosis risk syndrome (McGlashan, Walsh, \& Woods, 2010). Each EASA program follows practice 
guidelines consistent with best practices in early psychosis, including assertive community outreach, supportive counseling, family psychoeducation, medication interventions, supported employment and education.

\section{Characterizing the DUP period: from first symptom to first treatment.}

The pathway to care during the DUP period has been characterized by help-seeking and system contact or alternately, supply-side and demand-side factors (Srihari, et al, 2014). Studies have found mental health system contact delays contribute to longer DUP when compared with help-seeking delays (Birchwood, et al, 2013) or that DUP is evenly impacted by both types of delays (O'Callaghan, et al, 2010). In addition to system-related delays, the help-seeking phase has been characterized by variation in symptom presentation with primary negative or affective symptoms being associated with a longer DUP than positive symptoms (Bechard-Evans, et al, 2007; Compton, et al, 2011; Drake, et al, 2000). Residing with family prior to first hospitalization has been found to prolong a DUP (Compton, et al, 2011) while many more studies found associations between family involvement and a shortened DUP (Compton, et al, 2008; Morgan, et al, 2006; O’Callaghan, et al, 2010). Qualitative aspects of family involvement associated with DUP are beliefs and knowledge about mental illness, fear of stigma and coping mechanisms (Compton, et al, 2009; Ferrari, 2015; Franz, et al, 2010; Jackson, et al, 2002; Jansen, et al, 20XX; Tanskanen, et al, 2011) as well as explanations of behavior (Bhikha, et al, 2015; Compton, 2004; Del Vecchio et al, 2015; Tanskanen, 2011). All of these variables are subject to the unique cultural aspects of individual countries and regions.

This study seeks to examine the experiences of a sample of young adults from the EASA program to obtain pilot data about the DUP process in Oregon, defined here as the elapsed time between first symptom and first psychiatric treatment. At the time of this study, EASA had limited data on the DUP period therefore this study proposed using qualitative methods to learn more about the DUP process.

\section{Method}

Researchers framed this study through the social constructivist lens, which posits that meaning is created through the interaction of people with their environment (Witkin, 2012) Grounded theory was used to "develop an explanatory theory of basic social processes, studied in the environments in which they take place" (Glaser \& Strauss, 1967 as cited in Starks \& Trinidad, 2007). Researchers sought out the experiences of clients with FEP served by EASA and their family members. The research team consisted of a clinical consultant to early intervention 
programs around the country, a researcher with interest and experience with the population, and an EASA graduate involved with community education about the early intervention program. All three researchers had existing knowledge about the program, early psychosis, and the DUP phenomenon.

\section{Sample}

After receiving IRB approval from Portland State University, the research team used purposive sampling to recruit both young adults who had experienced psychosis and their parents or guardians into the study in order to gain depth into the DUP experience. A convenience sample was recruited from the urban population of greater Portland and an area, representing a smaller community just southwest of the Portland area. Flyers were posted at the respective early intervention programs and in most cases clients and/or their family members directly contacted the researchers, with a few exceptions where an early intervention program clinician made a connection between the client and the research team. Inclusion criteria were having a diagnosis of early psychosis (e.g. psychosis, NOS; schizophrenia; schizoaffective disorder), age 18-30, and involved in the early intervention program for at least 6 months at the time of the interview. Family members were either a parent or legal guardian during the period preceding admission to the early intervention program and were interviewed in dyads in one case. All clients were interviewed separately from their parents. Each party interviewed received $\$ 30$ cash as compensation for their time.

\section{Data Collection and Analysis}

All three researchers also served as interviewers. Interview questions were developed to be representative of the DUP period which was defined as beginning with first identified symptom of psychosis and ending with first psychiatric treatment. Semi-structured interviews began with asking about the period when the clients or family member realized there was a mental change, followed by asking questions about the process of searching for help, and ended by asking about the process of beginning to work with the early intervention program. Interviews lasted from 30 minutes to one hour and were audiotaped. Confidentiality was explained thoroughly at the time of consent and all participants were assured that the actual early intervention program clinical site would not have access to their interview. Pseudonyms were used to de-identify names and identifying information was deleted during the transcription process. The de-identified interview transcripts were uploaded into Dedoose software program, version 6.1.18 for analysis (2015).

Grounded theory method suggests that a study "fits the empirical world when you have constructed codes and developed them into categories that crystallize participants' experience" (Charmaz, 2006, p. 54). Interview 
transcripts were coded independently and each individual researcher began with an unmarked copy. Researchers independently coded themes across all transcripts using an open coding process. After each successive open coding series, the research team met and discussed core theme areas, using an iterative process to reach the core categories. The research team then used individual memo writing to move theme generation from initial to intermediate coding and resolved any discrepancies through discussion. Theoretical sufficiency was reached through the process of "finding the negative case," which resulted in the addition of a new category when a case did not "fit" within the original core categories (Charmaz, 2006). Later, researchers used advanced coding to develop the final, more detailed model, which enhanced the relationships between variables and overall social processes of the clients and their family members.

The research was approved by Portland State University's Human Subjects Research Review Committee, proposal \#142945. The authors have no conflicts of interest to disclose related to this study and certify their responsibility for the manuscript. The authors certify (a) that they accept responsibility for the conduct of the study and for the analysis and interpretation of the data, (b) that they helped write the manuscript and agree with the decisions about it, (c) that they meet the definition of an author as stated by the International Committee of Medical Journal Editors, and (d) that they have seen and approved the final manuscript.

\section{Results}

A total of 15 interviews occurred, representing the experiences of ten clients (mean age $=24$ ) who had experienced a first episode of psychosis before entering the early intervention program in Oregon. One client interviewed had clearly described a manic episode and later bipolar diagnosis so this case was removed from the final analysis for a total sample size of nine clients.

Two core categories had the most influence on DUP across all interviews: recognition of symptoms and the presence or absence of supportive others. Recognition of symptoms was influenced by a subtheme of symptoms and signs such as whether hallucinations or delusions were present and visible physical deterioration. In most cases, presence of supportive others (e.g., family or professional) combined with recognition of symptoms ultimately impelled taking action to seek treatment. When supportive others were not present, recognition was delayed and arrest ultimately ended DUP. As arrest was found to influence DUP independent of recognition and presence of supportive others, it is considered an additional theme. Finally, some young adults were resistant to their family 
member bringing the early intervention program staff into the home which complicated the engagement needed to treat and end DUP.

\section{Core Categories: Recognition of Symptoms and Presence or Absence of Supportive Others}

Two interacting core categories, recognition of psychosis symptoms and presence or absence of supportive others, ultimately influenced the help-seeking process. Recognition of symptoms occurred either by the individual with psychosis or a by a close family member. The next sections describe how symptoms and signs interacted with the presence or absence of supportive others. In contrast, absence of supportive others in the individual's life prolonged the DUP, as illustrated in the excerpt below:

"Well yeah, before [arrest] it was like a year. Things were like happening, and people could have noticedor maybe half a year - and actually people did notice. My friend said to my mom, He's not acting the same. Anyway, I dropped out of college, and maybe that could have been taken as a hint, like something's not right."

This case was compelling in that it illustrated how lack of regular contact with supportive others prolonged DUP in contrast with all other cases. The next section describes how the presence of supportive others interacts with symptom type to facilitate or hinder recognition and help-seeking.

\section{Symptoms and signs.}

The core categories of recognition of symptoms and presence of supportive others were found to be influenced by symptom-type and signs of physical deterioration. Across cases, it was the emergence of first positive symptom (e.g., hallucinations, delusions) which prompted recognition by the individual or supportive others. However, we noticed a different trajectory of recognition when delusions were present in comparison to those who experienced auditory hallucinations-only. These different trajectories of recognition by symptom-type are explained below.

\section{Hallucinations-only facilitated recognition.}

When an individual recounted hallucinations-only as the first positive symptom, they reported recognizing this as "something wrong" and usually told a parent or existing counseling professional $(n=3)$. This quote is from a participant who called his mother while away and told her about hearing voices: 
"I'd already spent a couple days on the phone with my mom, not really knowing what to do, ...she's the one who mentioned, look, if it gets bad enough, you need to just check yourself into the hospital. So I went."

In this example, the young adult was hearing voices, recognized the change and called a parent, which led toward help-seeking. Two additional participants confided in their existing professional helpers (e.g. counselors) that they were hearing voices, which prompted the professional helpers to make a referral to EASA. In these cases, there were few if any barriers between symptom recognition and beginning the help-seeking process.

Presence of delusions complicated recognition.

In most cases where delusions were present either alone $(n=2)$ or mixed with hallucinations $(n=4)$ as the first positive symptoms, individual recognition of a psychotic symptom was absent, and thus an external person was the first to come to recognize the delusion as psychosis. In one example, a client explains, retrospectively, how he may have recognized a new pattern of thoughts (i.e. delusions) but at the time failed to interpret them as psychosis.

"I didn't think about it reasonably, like scientifically or even like objectively or straightforward. I wasn't questioning why I was thinking that way because I was just thinking that way. It was more like I was believing in this certain way, I wasn't thinking in a certain way."

Here, the participant did not individually recognize his changes in thoughts as symptoms of psychosis.

In addition to delusions complicating individual recognition, family members in our study misinterpreted delusional symptoms as behaviors or symptoms of a mood disorder rather than psychosis. This misinterpretation of psychosis resulted in a delay in taking action. In one case, reasoning occurred in response to delusional thinking rather than seeking professional help.

"I remember having conversations with him, and trying to reason with him, and then there were points when, you know I never saw him cry very much, but one time he was crying because it was very frustrating thinking that people were out to get him or whatever".

This family member dealt with the psychosis at home for 2-3 months before an escalation in symptoms resulted in a deterioration of physical health, and only then took action. This phenomenon is described in the next section.

Different symptom-type, defined here as the emergence of hallucinations and/or delusional thoughts, led to very different recognition and help-seeking processes in our sample, with hallucinations-only facilitating individual 
recognition and delusions complicating recognition in general. The process of recognition here was also influenced by the presence of significant others.

\section{Physical deterioration prompts action by family.}

In two cases where delusions were present and family delayed taking action, "visibility" of a physical deterioration in their child ultimately impelled help-seeking.

"I knew it wasn't...something... why was he doing this? I didn’t understand why...it just didn’t seem like, if you want to call it normal behavior. About a few nights later again we couldn't find him and it was extremely cold...he's in the garage buck naked, sitting on the cement doing some sort of prayer. I mean it was really cold, it was December, no clothes on, praying...that's when we knew something was really, really getting... and at that time of course I noticed he was extremely thin.”

In this case, the family member describes her own confusion about the young person's behavior, which escalated into taking immediate action when she observed his deteriorating physical condition as a result of having stopped eating in response to delusional thoughts. Up until this point, the family member reported a period of uncertainty about the behavioral changes. The next excerpt illustrates a similar scenario for a parent:

“...it was very frustrating because first of all I had never experienced this before, second of all I didn’t know what in the world to do because I think he was over 18 at the time, and it's like unless we were suggesting that he needed help... and he thought everything was perfectly normal, he thought this was...that there wasn't anything wrong with his behavior, and around the same time period he got [infection in wound], and then he had just decided in his mind he didn't want to go see his doctor, and he thought his doctor was out to get him and...I feel like it was even a miracle that we got him to the hospital. Somehow we got him into our van and drove him to the emergency room."

This parent describes a time period of unsuccessful reasoning to seek treatment until a serious infection prompted an immediate emergency room visit. Both of these family members dealt with the psychosis at home for 2-3 months before an escalation in symptoms resulted in a deterioration of physical health, and only then took action.

\section{Arrest facilitates action.}

A theme of arrest emerged from our interview transcripts, with $(n=2)$ participants arrested while acting on either command hallucinations or delusional thoughts. Arrest in these cases happened before recognition of symptoms and ended the DUP through direct psychiatric treatment. 


\section{Resistance to family-initiated early intervention outreach.}

A final theme in our study was resisting treatment when family initiated contact and then received outreach from the early intervention program $(n=2)$.

"It was never my choice, it was my family's choice. I started having a lot of delusional thinking and my family contacted \{early-intervention program], without my permission or understanding. I just came into the living room and she was here, and talked to me....I was upset with my family and the counselor because they didn't believe me about what I was seeing and experiencing. They thought that I was hallucinating but I said that it was real, that I could just see it, and so I was really upset with my family. I resisted a lot of my treatment and everything for a long time."

This participant outlines their feelings of frustration with the family decision to bring mental health professionals into the home. This case also illustrates non-recognition of delusional symptoms, which in combination with outreach to the home, created more resistance. Another young adult describes the family involvement in early intervention outreach as a negative experience:

\footnotetext{
"I hated it at first because like, I didn't want to come here. Like, I did, but I didn't like that my family would be involved in my treatment, because...um... so I...actually after my first meeting with (staff) with my mom being there- I ended up running away after it. And then I got sent to the hospital again...well it made me really upset, and like all the problems they had with me, that's why I ran away. And the voices wanted me to run away, too."
}

In both of these cases, the young adult's interpretation of family involvement in treatment was the impetus for more resistance to receiving treatment, indicating that while the presence of a supportive person did facilitate the end of DUP in most cases, this may be particularly difficult without individual recognition of psychosis. This has implications for the engagement protocols of early intervention teams. See Figure 1.

\section{Discussion}

In summary, our study aims were to explore the DUP experiences of local young adults between the first positive symptom of psychosis and first psychiatric treatment. Our study revealed core themes of recognition of psychosis and presence or absence of significant others which interacted together to influence help-seeking. Help- 
seeking and arrest immediately ended DUP as they were the entry to psychiatric treatment except in two cases where the young adult was resistant to family and early intervention outreach. The following discussion contains a review of previous studies across these themes.

\section{Intersection between Symptom Recognition and Presence of Supportive Persons.}

Recognition of psychosis in this study was greatly affected by the type of positive symptom experienced, with hallucinations-only leading to earlier recognition and subsequent help-seeking by the individual. In contrast, the presence of delusions led to complications in the help-seeking pathway, both by the young person and the family member. In addition to recognition, regular contact with a supportive person such as family or professional counselor facilitated the help-seeking process whereas absence of this supportive person prolonged the DUP.

Many DUP studies have focused on the explanatory process of recognizing psychosis, all indicating that the appearance of positive symptoms is generally the catalyst for recognition (De Haan, et.al., 2002; Bay, Bjørnestad, Johannessen, Larsen, \& Joa, 2014; Compton Potts, Wan, \& Ionescu, 2012; Compton, et, al., 2012; Bergner, Leiner, Carter, Franz, Thompson \& Compton, 2008; Judge et. al., 2008) while the prodromal period is not recognized. Other studies have found recognition to be a major aspect of DUP, both in terms of no, partial, or full awareness (De Haan \& et., al., 2002) and a complete failure to recognize symptoms except auditory hallucinations (Bay, et. al., 2014). One study found that simultaneous hallucinations/delusions led to a shorter DUP than either one preceding the other (duration-1 month) or either alone and that the delusion-only group had a shorter DUP than the combined delusion-hallucination group (Compton, et, al., 2012) On the other hand, (Okasha, et al, 2016) found that more acute psychotic episodes were associated with a shorter DUP than delusional disorder, which had a longer DUP. Indeed, in cases where delusions were vivid and severe in our study, they became more visible and prompted immediate intervention (e.g. arrest) however, their presence still delayed recognition and action in the majority of cases. If positive symptoms are the catalyst for detection, with auditory hallucinations linked with a faster initiation of help-seeking, this has important implications for reducing DUP in its early stages.

Contact with supportive persons - usually a parent/guardian, but also professionals, facilitated the helpseeking process. This core category interacted with individual recognition in that young adults told supportive others about their hallucinations while those with delusions depended on contact with supportive others to facilitate 
help-seeking. Parents of those young adults with delusional ideation struggled to make sense of the symptoms and this prolonged the DUP process. Multiple studies in a global context describe different reasoning processes among family members, including creating explanatory models (Sin, Moone, \& Harris, 2008; Larsen, Johannessen \& Opjordsmoen, 1998; Ahari, Nikpou, Molavi, Abdi, Amani \& Shirinzadeh, 2014) and attributing behavior changes to traditional ideas such as demons (Monteiro, dos Santos, \& Martin, 2006). Another common finding is the misattribution of symptoms of psychosis to negative behavior such as drug use or teenage "acting out" (Bergner, et, al., 2008; Corcoran, Gerson, Sills-Shahar, Nickou, McGlashan, Malaspina, \& Davidson, 2003; Skubby, Bonfine, Tracy, Knepp, \& Munetz, 2015). While family involvement is likely a crucial factor in identification of psychosis symptoms and pursuing a path to treatment, this interpretive process is subject to cultural and societal influences (Hernandez, Barrio, \& Yamada, 2013; Doyle,Turner, Fanning, Brennan, Renwick, Lawlor \& Clarke 2014). Finally, one individual with both delusional thoughts and no contact with supportive others, had the longest DUP period in our study. This could indicate that presence of delusions coupled with lack of contact with others could be "double trouble" in prolonging DUP.

\section{"Visibility" of Deterioration.}

In two cases where delusions-only were the positive symptom and family did not act, a medical emergency was the catalyst to prompt an emergency room visit, leading to subsequent psychiatric hospitalization and treatment. Other studies have characterized this as "the breaking point" (Corcoran, Davidson, Sills-Shahar, Nickou, Malaspina, Miller \& McGlashan, 2003). As physical changes are more apt to be visible and therefore more obvious than mental changes, this phenomenon seems fairly straightforward. On the other hand, this phenomenon could be representative of a Western-influenced culture that tends to socially accept physical illness but use behavioral explanations for mental illness. Many studies have found stigma to be a barrier to accessing early intervention (Boydell, et. al., 2010; Tanskanen, Morant, Johnson, 2011; Franz, Carter, Leiner, Bergner, Thompson, Compton, 2010; Gladstone, Volpe, \& Boydell, 2007; Jansen, Wøldike, Haahr \& Simonsen, 2015; Ahari, Nikpou, Molavi, Abdi, Amani \& Shirinzadeh, 2014; Lloyd-Evans, Sweeney, Hinton, Morant, Pilling, Leibowitz, Killaspy, Tanskanen, Totman, Armstrong \& Johnson, 2015; Jansen, Woldike, Haahr, \& Simonsen, 2015) but data tends to be vague regarding whether the issue is stigma or lack of awareness about mental illness. As the visible health vs. 


\begin{abstract}
Arrest Ends DUP
Severity of psychosis in our study led to arrest in two cases, in one case the client was arrested after acting upon command hallucinations while the other reported delusions-only and had a relatively long DUP before arrest (Gerson, Davidson, Booty, McGlashan, Malespina, Pincus \& Corcoran, 2009).
\end{abstract}

\title{
Limitations and Implications for Practice
}

Given our small sample size and very limited local context of EASA within Oregon, this study can only be seen as representational of those experiences. We only interviewed parents or guardians in addition to young adults which limits the scope of all DUP experiences, such as those described by inpatient psychiatric treatment providers. We did not include those clients who are not under care of the early intervention program and/or not in formal care. However, despite these limitations a small sample size did allow us to focus in on the social processes and personal experiences of psychosis recognition and search for help, highlighting unique experiences with interpreting first positive symptom and function of intermediary support. These results indicate a need for further study of individual experiences and social processes during the first-episode period. 


\section{References}

Ahari S., Nikpou, H., Molavi, P., Abdi R., Amani, F., Shirinzadeh B. (2014). An investigation of duration of untreated psychosis and the affecting factors. Journal of Psychiatric and Mental Health Nursing. 21(1):87-92.

Addington, J., Van Mastrigt, S., Hutchinson, J., \& Addington, D. (2002). Pathways to care: help seeking behaviour in first episode psychosis. Acta Psychiatrica Scandinavica, 106(5), 358-364.

Anderson, K., Flora, K., Archie, N., Morgan, S., \& McKenzie, C. (2014). Race, ethnicity, and the duration of untreated psychosis: A systematic review. Social Psychiatry and Psychiatric Epidemiology, 49(7), 1161-1174.

Bay, N., Bjørnestad, J., Johannessen, J.O., Larsen, T., K \& Joa, I. (2014). Obstacles to care in first-episode psychosis patients with a long duration of untreated psychosis. Early Intervention in Psychiatry. 8(4):323-31

Bechard-Evans, Schmitz, Abadi, Joober, King, \& Malla. (2007). Determinants of help-seeking and system related components of delay in the treatment of first-episode psychosis. Schizophrenia Research, 96(1), 206-214.

Bergner, E., Leiner, A.S., Carter, T., Franz, L., Thompson, N.J., Compton, M.T. (2008). The period of untreated psychosis before treatment initiation: a qualitative study of family members' perspectives. Comprehensive Psychiatry. 2008; 49:530-538.

Birchwood,M., Connor, C., Lester,H., Patterson, P., Freemantle,N., Marshall, M., Fowler, D., Lewis, S., Jones, P., Amos, T., Everard, L., \& Singh, S., P. (2013). Reducing duration of untreated psychosis: Care pathways to early intervention in psychosis services. The British Journal of Psychiatry: The Journal of Mental Science, 203(1), 58-64.

Boydell, K. M, Staisluis, E., Volpe, T., \& Gladstone, T. (2010). A descriptive review of qualitative studies in first-episode psychosis. Early Intervention in Psychiatry, 4 (1): 7-24.

Byrne, R., \& Morrison, A. P. (2010). Young people at risk of psychosis: a user-led exploration of interpersonal relationships and communication of psychological difficulties, Early Intervention in Psychiatry, 4, 162-168. 
4 Charmaz, K. (2006). Constructing grounded theory: a practical guide through qualitative analysis. London: Sage Publications.

Compton, Goulding, Gordon, Weiss, \& Kaslow. (2009). Family-level predictors and correlates of the duration of untreated psychosis in African American first-episode patients. Schizophrenia Research, 115(2-3), 338-345.

Compton, M., Chien, T., Leiner, V., Goulding, H., \& Weiss, A. (2008). Mode of onset of psychosis and family involvement in help-seeking as determinants of duration of untreated psychosis. Social Psychiatry and Psychiatric Epidemiology, 43(12), 975-982.

Compton, M., Gordon, T., Goulding, S., Esterberg, M., Carter, T., Leiner, A., . . Kaslow, N. (2011). Patient-level predictors and clinical correlates of duration of untreated psychosis among hospitalized first-episode patients. The Journal of Clinical Psychiatry, 72(2), 225-32.

Compton, Kaslow, \& Walker. (2004). Observations on parent/family factors that may influence the duration of untreated psychosis among African American first-episode schizophrenia-spectrum patients. Schizophrenia Research, 68(2), 373-385.

Compton, M., Gordon, T., Weiss, P., \& Walker, E. (2011). The "doses" of initial, untreated hallucinations and delusions: A proof-of-concept study of enhanced predictors of first-episode symptomatology and functioning relative to duration of untreated psychosis. The Journal of Clinical Psychiatry, 72(11), 1487-93.

Compton, M.T., Potts, A. A., Wan, C.R., Ionescu, D.F. (2012). Which came first, delusions or hallucinations? An exploration of clinical differences among patients with first-episode psychosis based on patterns of emergency of positive symptoms. Psychiatry Research, 200:702-707.

Corcoran, C., Davidson, L., Sills-Shahar, R., Nickou, C., Malaspina, D., Miller, T., McGlashan, T., A. (2003). Qualitative Research Study of the Evolution of Symptoms in Individuals Identified as Prodromal to Psychosis. Psychiatric Quarterly, 74(4): 313-332.

Corcoran, C., Gerson, R., Sills-Shahar, R., Nickou, C., McGlashan,T., Malaspina, D., Davidson, L. (2007). Trajectory to a first episode of psychosis: a qualitative research study with families. Early Intervention in Psychiatry, 1:308-315.

Del Vecchio, V., Luciano, M., Sampogna, G., De Rosa, C., Giacco, D., Tarricone, I., Catapano, F. \& Fiorillo, A. (2015). The role of relatives in pathways to care of patients with a first episode of psychosis. International Journal of Social Psychiatry, 61(7), 631-637.

Dedoose Version 6.1.18, web application for managing, analyzing, and presenting qualitative and mixed method research data (2015). Los Angeles, CA: SocioCultural Research Consultants, LLC (www.dedoose.com).

De Haan, L., Peters, B., Dingemans, P., Wouters, L., \& Linszen, D. (2002). Attitudes of patients toward the first psychotic episode and the start of treatment. Schizophrenia Bulletin, 28(3): 431-442.

Doyle, R.,Turner,R., Fanning, F.,Brennan,D., Renwick, L., Lawlor, E., \& Clarke, M. (2014). First-episode psychosis and disengagement from treatment: a systematic review. Psychiatric services: A journal of the American Psychiatric Association, 65 (5), 603-611. 
4 Drake, R.W., Haley, C.J., Akhtar, S. \& Lewis, S.W. (2000). Causes and consequences of duration of untreated psychosis in schizophrenia. The British Journal of Psychiatry, 177(6) 511-515.

Ehmann, T., Tee, K., MacEwan, G., Dalzell, K., Hanson, L., Smith, G., . Honer, W. (2014). Treatment delay and pathways to care in early psychosis. Early Intervention in Psychiatry, 8(3), 240-246.

Ferrari M. (2015). The African, Caribbean and European (ACE) Pathways to Care study: A qualitative exploration of similarities and differences between African-origin, Caribbean-origin and European-origin groups in pathways to care for psychosis, BMJ Open., 5(1), E006562.

Franz L., Carter T., Leiner, A., Bergner, E, Thompson, N., Compton, M. (2010). Stigma and treatment delay in first-episode psychosis: A grounded theory study. Early Intervention in Psychiatry, 4(1):47-56.

Gerson, R., Davidson, L., Booty, A., McGlashan, T., Malespina, D., Pincus, H.A.\& Corcoran, C. (2009). Families' experience with seeking treatment for recent - onset psychosis. Psychiatric services: A Journal of the American Psychiatric Association, 60(6):812-6.

Gladstone, B.M., Volpe, T., Boydell, K., M. (2007). Issues encountered in a qualitative secondary analysis of help-seeking in the prodrome to psychosis. Journal of Behavioral Health Services and Research, 34(4): 431-442.

Hernandez, M., Barrio, C., \& Yamada, A.M. (2015). Hope and burden among Latino families of adults with schizophrenia. Community Mental Health Journal, 51(8): 939-948.

Jackson, C, Birchwood, M, Jones, C, \& Skeate, A. (2002). Duration of untreated psychosis and pathways to care in firstepisode psychosis: Investigation of help-seeking behaviour in primary care. The British Journal of Psychiatry, 181(43), 73s-77.

Jansen, J., Wøldike, P., Haahr, U., \& Simonsen, E. (2015). Service user perspectives on the experience of illness and pathway to care in first-episode psychosis: A qualitative study within the TOP project. Psychiatric Quarterly, 86(1), 83-94.

Jordan, G., MacDonald, K., Pope, MA., Schorr, E., Malla, AK., \& Iyer, S.N. (2018). Positive changes experienced after a first episode of psychosis: a systematic review. Psychiatric services: a journal of the American Psychiatric Association, 69(1):84-99.

Judge, A. M., Estroff, S., E., Perkins, D.O., Penn, D., L. (2008). Recognizing and responding to early psychosis: a qualitative analysis of individual narratives. Psychiatric Services, 59(1):96-99.

Larsen T. K., Johannessen, J. O., Opjordsmoen, S. (1998). First-episode schizophrenia with long duration of untreated psychosis: pathways to care. British Journal of Psychiatry. Supplements 172:45-52.

Lincoln C., Harrigan S., McGorry, P. (1998). Understanding the topography of the early psychosis pathways. British Journal of Psychiatry, 172(Suppl. 33): 21-25.

Lutgens, D., Malla, A., Joober, R., \& Iyer, S. (2015). The impact of caregiver familiarity with mental disorders on timing of intervention in first-episode psychosis. Early Intervention in Psychiatry, Early Intervention in Psychiatry, 9(5):38896. 
4 O’Callaghan, E., Turner, N., Renwick, L., Jackson, D., Sutton, M., Foley, S., . . Kinsella, A. (2010). First episode psychosis and the trail to secondary care: Help-seeking and health-system delays. Social Psychiatry and Psychiatric Epidemiology, 45(3), 381-391.

Okasha,T., Zaki, N., Meguid, M., El-Missiry, M., Sabry, W., Kamel Ismaeil, M. \& Fouad F., M. (2016). Duration of untreated psychosis in an Egyptian sample: Sociodemographic and clinical variables. International Journal of Social Psychiatry, 62 (7): 661-671.

McGlashan, T, Walsh, B, \& Woods, S. (2010). The Psychosis-risk syndrome: handbook for diagnosis and follow-Up. 2010. New York: Oxford University Press.

Melton, R. P., Roush, S. N., Sale, T. G., Wolf, R. M., Usher, C.T., Rodriguez, C.L., \& McGorry, P.D. (2013). Early intervention and prevention of long-term disability in youth and adults: The EASA model. In K.Yeager, D. Cutler, D. Svendsen and G.M. Sills, (eds.) Modern Community Mental Health: An Interdisciplinary Approach. 256-277.

Monteiro, V. B. M., dos Santos, J.Q., Martin, D. (2006). Patients' relatives delayed help seeking after a first psychotic episode. Rev Bras Psiquiatr,28(2):104-10.

Morgan, Craig, Abdul-Al, Rudwan, Lappin, Julia M, Jones, Peter, Fearon, Paul, Leese, Morven, . . Murray, Robin. (2006). Clinical and social determinants of duration of untreated psychosis in the AESOP first-episode psychosis study. The British Journal of Psychiatry:The Journal of Mental Science, 189, 446-52.

Schaffner, N., Schimmelmann, B., Niedersteberg, A., \& Schultze-Lutter, F. (2012). Pathways-to-Care for First-Episode psychotic patients--an overview of international studies. Fortschritte Der Neurologie-Psychiatrie, 80(2), 72-8.

Sin, J., Moone, N., Harris, P. (2008). Siblings of individuals with first-episode psychosis: Understanding their experiences and needs. Journal of Psychosocial Nursing and Mental Health Services. 2008; 46(6): 33-40.

Skubby, D., Bonfine, N., Tracy, H., Knepp, K., Munetz, M., M. (2015). The help-seeking experiences of parents of children with a first-episode of psychosis. Community Mental Health Journal, 51(8): 888-896.

Srihari, V.H., Tek, C., Pollard, J., Zimmet, S., Keat, J., Cahill, J.D., . . Woods, S.W. (2014). Reducing the duration of untreated psychosis and its impact in the U.S.: The STEP-ED study. BMC Psychiatry, 14, 335.

Starks, H., Trinidad, B., S. (2007). Choose Your Method: A Comparison of Phenomenology, Discourse Analysis, and Grounded Theory. Qualitative Health Research Journal, 17(10):1372-80.

Tanskanen S., Morant, N., Hinton, M., Lloyd-Evans, B., Crosby, M., Killaspy, H., Raine, R., Pilling, S., Johnson, S. (2011). Service user and carer experiences of seeking help for a first episode of psychosis: A UK qualitative study. BMC Psychiatry, 11:157.

Temmingh, H., \& Oosthuizen, S. (2008). Pathways to care and treatment delays in first and multi episode psychosis. Social Psychiatry and Psychiatric Epidemiology, 43(9), 727-735. 
1

2

3

4 Witkin, S. L. (2012). Social construction and social work practice: interpretations and innovations. New York: Columbia $5 \quad$ Press.

7

8

9

10

11

12

13

14

15

16

17

18

19

20

21

22

23

24

25

26

27

28

29

30

31

32

33

34

35

36

37

38

39

40

41

42

43

44

45

46

47

48

49

50

51

52

53

54

55

56

57

58

59

60

61

62

63

64

65 
Figure 1. Help-Seeking Process 


\section{Presence of Significant Others}
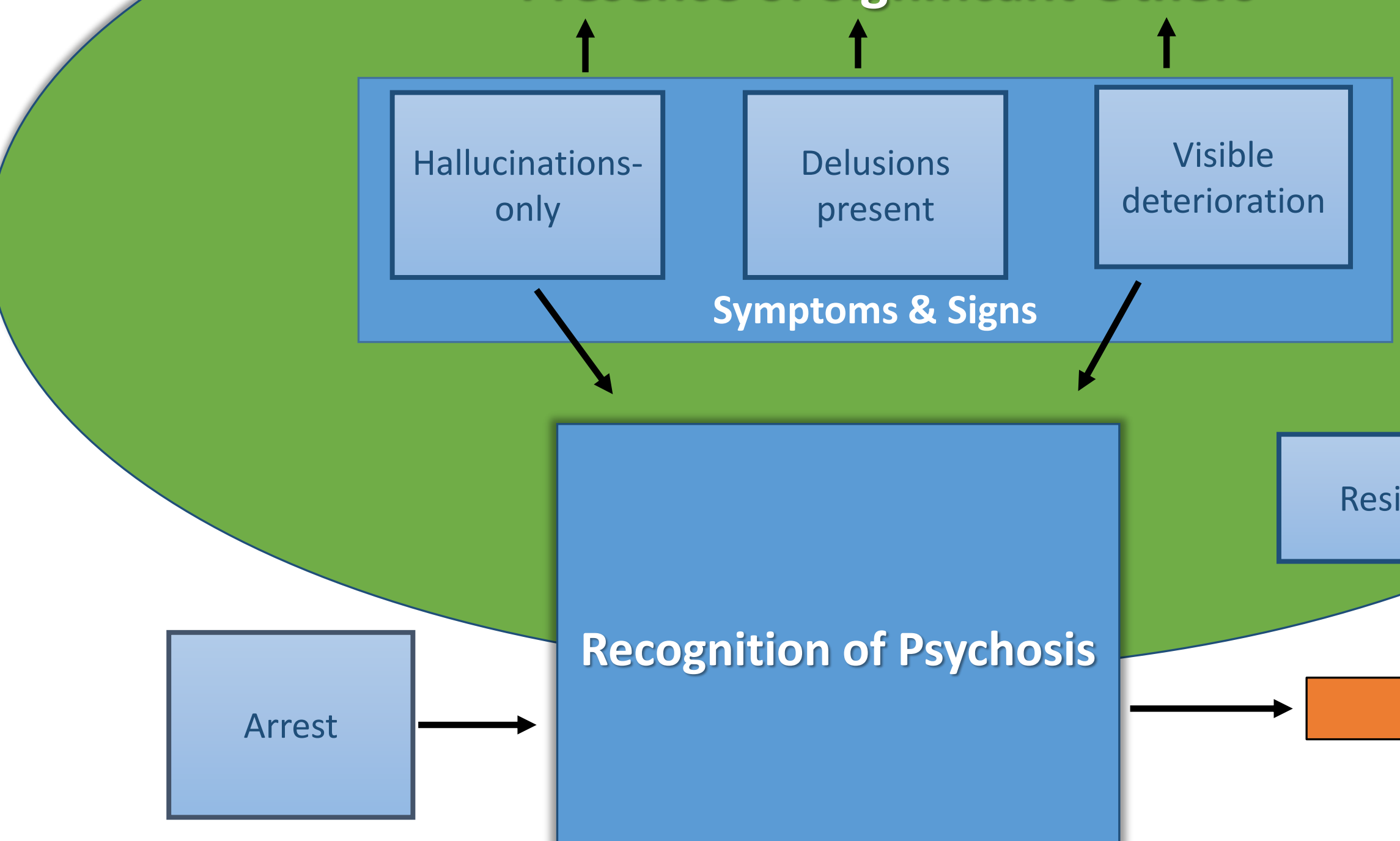

Recognition of Psychosis
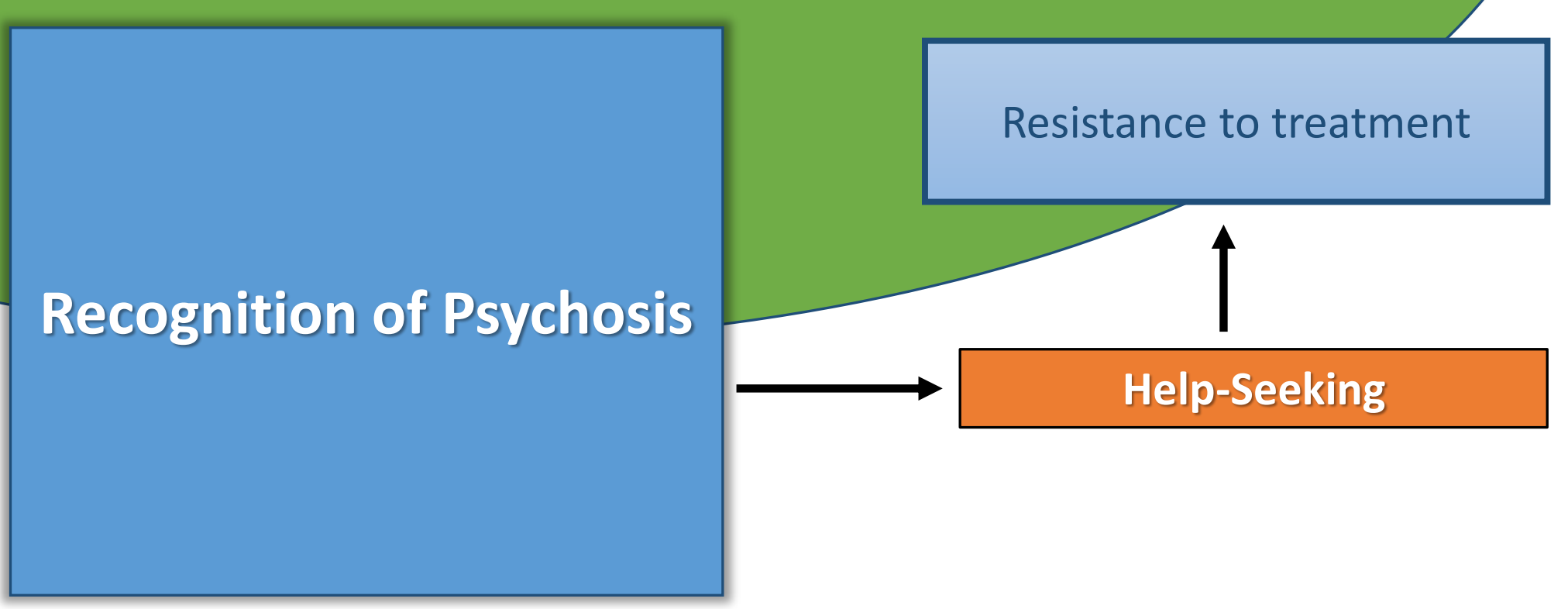

Help-Seeking 